\title{
Internal Humanitarian Outreach in ENT (Senegal - Guinea Conakry)
}

\author{
Evelyne S Diom ${ }^{1 *}$, Ciré Ndiaye ${ }^{2}$, Mouhamadou Barry ${ }^{2}$, Souleymane Maiga ${ }^{2}$, Houra Ahmed ${ }^{2}$ and Pilor Ndongo ${ }^{2}$ \\ ${ }^{1}$ Department of ORL and head and neck surgery, University of Assane Seck, Senegal \\ ${ }^{2}$ Department of Otolaryngology, University of Cheikh Anta DIOP Dakar, Senegal
}

*Corresponding author: Diom ES, Associate professor in department of ORL and head and neck surgery, University of Assane Seck, Senegal

\begin{abstract}
Goal: The purpose of this study is

a) To describe a new "system of cooperation" within the same country.

b) To report the surgical activities, specialized consultations and academic teaching carried out during these missions.

c) To describe the difficulties encountered during missions in rural areas and the bilateral benefits of such missions for the population, the local team and the 2 humanitarian workers.

Methods: it's a retrospective study of missions carried out by the same team, covering a period of 11 years in 13 regions of Senegal and in Guinea Conakry.

Results: During the 61 humanitarian missions there were 5,702 consultations, 637 patients underwent surgery, and 10 postgraduate courses were conducted. The most common pathologies were chronic otitis media (22\%) and gastroesophageal reflux $(18 \%)$. The most common surgical procedures were thyroidectomy (25\%), tonsillectomy (17\%) and parotidectomy $(6 \%)$. Otology and rhinology encountered real constraints; complex procedures such as laryngectomy, trans maxillary bucco-pharyngectomy and mandibulectomy were performed.

Conclusions: These missions have enabled people living in remote areas to benefit from quality care, highlighted the clear disparity in the distribution of ENT services, and provided medical-scientific teaching to the staff.
\end{abstract}

Keywords: Humanitarian mission; remote regions of Senegal; ENT practice; outreach

\section{Introduction}

Otorhinolaryngology is a specialty that is not very accessible to the Senegalese population because the services and the qualified personnel are very insufficient. In Senegal there are 35 otorhinolaryngologists (ENTs) [1] for 13 regions (Figure 1). Six (6) of these specialists are concentrated in Dakar and the rest are divided between Ziguinchor, Thies, Diamniadio, Saint Louis, Touba, Diourbel and Kaolack. This is a very insufficient number for a population of 14,799,859 inhabitants spread accross the 14 regions of Senegal. It amounts to 1 ENT for 423,000 habitants, whereas the World Health Organization (WHO) recommends 1 ENT for 25,000 inhabitants [2]. Because of this shortage of ENT services, and large underserved areas the FANN's ENT department of Dakar, under the direction of Professor EM DIOP, in collaboration with the Embassy of Thailand, initiated missions of specialized care and teaching in 2005. The missions typically lasted five to six days and involved medical consultations, surgery, and postgraduate ENT teaching with lectures focusing on Senegalese ENT. The team was composed of a senior (assistant teacher or Professor), accompanied by an intern or a registrar from the Dakar Medical School. They were housed in a hotel or a residence in the area. One of the team members provided his/her vehicle for most missions. 


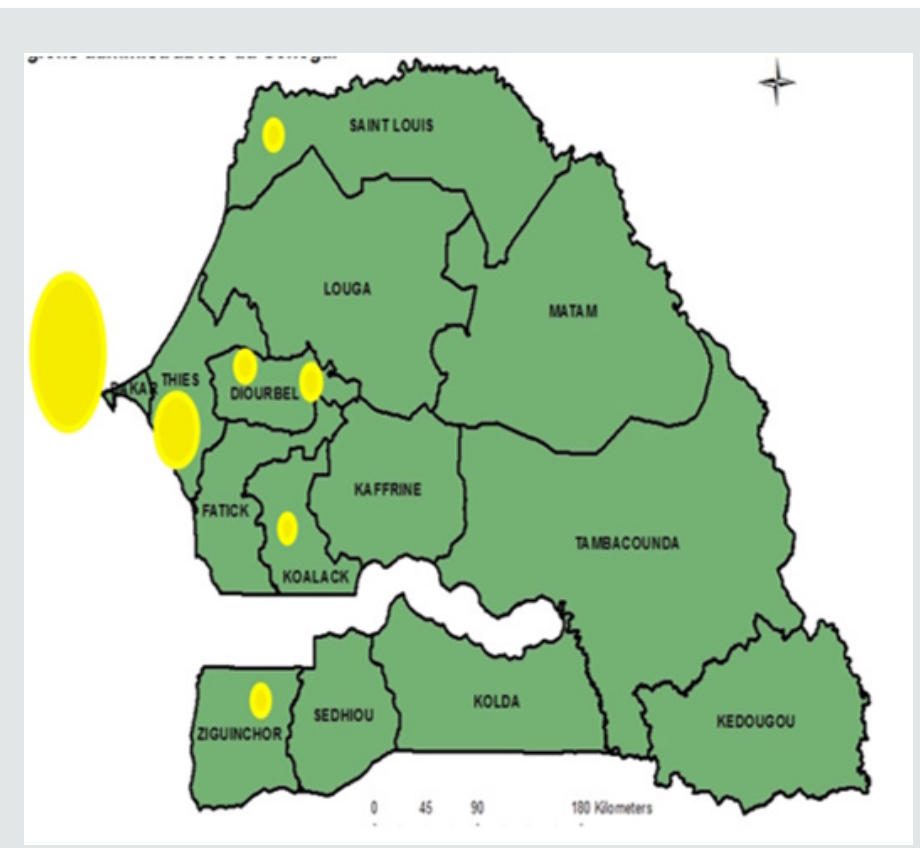

Figure 1: : Distribution of ENT specialists by region in Senegal in 2016 (1): Dakar 26, Ziguinchor 2, Kaolack 1, Diourbel 1, Louga 1; Saint Louis 1, Thies 3.

Source: ES Diom Collection

However, with missions in remote areas such as Ziguinchor or Sedhiou, the trip was made by plane. An ambulance purchased by the Thai Embassy was made available and served as a means of transport during some missions. Mission-related expenses (accommodations, meals, transportation) were covered in full by the Royal Thai Embassy; this generally amounted to between 500,000 and 700,000 CFA francs per mission? The equipment used for consultations and surgeries was mostly provided by the ENT team and often came from the FANN CHNU in Dakar. Radio broadcasts were used to sensitize the population and to increase participation in the missions. While the missions were not-for-profit, they were not totally free because, even though consultations were free, a fee was charged for surgical procedures. The follow-up of patients was done by the medical local team. Operated patients were evaluated before the end of the mission. Some patients requiring close followup for or further treatment were sent to Dakar. After 11 years of regular missions the same team, what are the real benefits, obstacles encountered, and lessons learned?

\section{Aim}

The purpose of this study is:

a. To describe a new "system of cooperation" within the same country.

b. To report the surgical activities, specialized consultations and academic teaching carried out during these missions.

c. To describe the difficulties encountered during missions in rural areas and the bilateral benefits of such missions for the population, the local team and the 2 humanitarian workers.

\section{Materials and Methods}

This is a retrospective study covering a period of eleven years (2005-2016) and set in the Republic of Guinea and in various regions of Senegal excluding Dakar. Thirteen cities in Senegal (Touba, Saint Louis, Louga, Ziguinchor, Kaolack, Tambacounda, Ourossogui, Sedhiou, Thies, Kedougou, Diourbel, Kolda and Linguere) benefitted from sixty-one (61) missions from 20052016. The data was derived from mission reports provided by those conducting the missions and were entered on an Excel 2013 spreadsheet. All patients who had an ENT consultation or surgical intervention were included in the study. At the end of each mission, a detailed daily report was compiled including the number of consultations, and for each patient the diagnosis, age, sex, address, treatment and additional investigations requested, indications for surgery; as well as incidents and difficulties encountered e.g. union strikes. At the end of each mission, a summary table of consultations and surgeries was completed. All the postgraduate courses taught during these missions were also reported and included. The followup of the patients was done on the spot, by the team of the mission first and later by the local doctor. The operated patients were evaluated before the team's departure. Some patients requiring close follow-up were transported to Dakar for further treatment. The reports were generated by the ENT doctors in the region, the ENT trainees assigned to the region, other specialists, generalists, nurses, and medical students. The data was analyzed with the Epi Info version 3.1 software and it's approved by the UCAD Research Ethics Committee (CER). 


\section{Results}

Our study focused on 40 of the 61 missions, as 21 missions were excluded from the study due to insufficient data. The missions started in 2005 in two cities, namely Tambacounda and Saint-Louis, then expanded over the years to other cities and also to Guinea Conakry (Table 1). In consultations (Table 2 \& Figure 2), the most frequently encountered pathologies were: chronic otitis media (22\%), gastroesophageal reflux (18.3\%), allergic rhinitis (15.1\%), tonsillitis (8.2\%), and goiter (2.3\%).
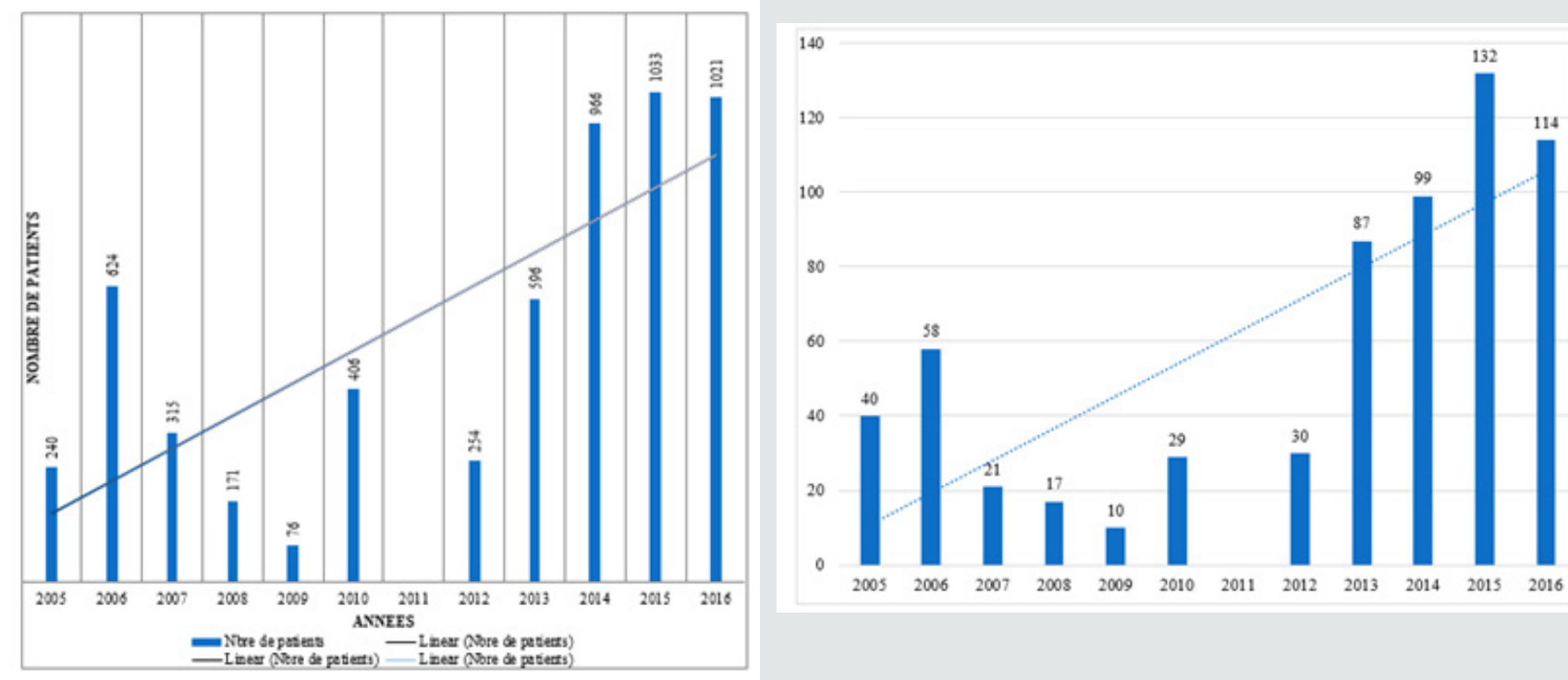

Figure 2a \& 2b: Diagrams of the numbers of patients consultations per year with trend line. Diagram of the number of surgical procedures performed per year with trend chart entered on Excel 2013

Table 1: Mission destinations to cities and Guinea Conakry.

\begin{tabular}{|c|c|}
\hline Year of Mission & Cities/ Countries \\
\hline 2007 & Saint-Louis, Ziguinchor, Touba, Tambacounda \\
\hline 2008 & Kaolack, Diourbel, Ziguinchor and Saint-Louis \\
\hline 2009 & $\begin{array}{c}\text { Thies, Kaolack, Tambacounda, Ziguinchor, Touba, } \\
\text { Guinea Conakry }\end{array}$ \\
\hline 2010 & Ziguinchor, Kaolack, Tambacounda, Touba, Louga \\
\hline 2011 & Tambacounda, Louga, Touba, Kaolack, Ziguinchor \\
\hline 2012 & $\begin{array}{c}\text { Diourbel, Saint-Louis, Ziguinchor, Tambacounda, } \\
\text { Linguère }\end{array}$ \\
\hline 2013 & $\begin{array}{c}\text { Tambacounda, Louga, Ziguinchor, Kaolack and Ou- } \\
\text { rossogui, Guinea Conakry }\end{array}$ \\
\hline 2014 & Louga, Ziguinchor, Kaolack, Touba, Sedhiou \\
\hline 2014 & $\begin{array}{c}\text { Touba, St. Louis, Ziguinchor, Kaolack, Tambacounda, } \\
\text { Sedhiou, Thies }\end{array}$ \\
\hline 2016 & $\begin{array}{c}\text { Kaolack, Tambacounda, Sedhiou, Kedougou, Ouros- } \\
\text { sogui, Kolda, Ziguinchor }\end{array}$ \\
\hline
\end{tabular}

Table 2: Numbers of patients seen in consultation per annum.

\begin{tabular}{|c|c|}
\hline Year & Number of consultations (\%) \\
\hline 2005 & $240(4,7 \%)$ \\
\hline 2006 & $624(10,9 \%)$ \\
\hline 2007 & $315(5,5 \%)$ \\
\hline 2008 & $171(3 \%)$ \\
\hline 2009 & $76(1,3 \%)$ \\
\hline 2010 & $406(7,1 \%)$ \\
\hline 2011 & $? ?$ \\
\hline 2012 & $254(4,5 \%)$ \\
\hline 2013 & $596(10,5 \%)$ \\
\hline 2014 & $966(16,9 \%)$ \\
\hline 2015 & $1033(18,1 \%)$ \\
\hline 2016 & $1021-17,90 \%$ \\
\hline Total & 5702 \\
\hline & \\
\hline & \\
\hline
\end{tabular}

\section{Surgeries are represented in Table 3.}

Total thyroidectomy was performed for Graves' disease, multinodular goiters, and thyroid cancers (Figures 3-5). The most frequently performed surgical procedures were: 
a) Thyroidectomy: $186(29.2 \%)$

b) Tonsillectomy; $105(16.5 \%)$ c) Adenotonsillectomy: $65(10.2 \%)$

d) The conservative total parotidectomy: 37 (5.8\%) (Figure 6).

Table 3: Summary table of surgical procedures.

\begin{tabular}{|c|c|c|}
\hline Surgical Procedure & Number & $\%$ \\
\hline Thyroidectomy & 186 & $29,2 \%$ \\
\hline Tonsillectomy +/-Adenoidectomy +/-noidectomie stes chirurgicaux. Adénoiedectomie & 200 & $31,4 \%$ \\
\hline Parotidectomy /Submandibulectomy/ ranula & 58 & $9,1 \%$ \\
\hline Endoscopy & 17 & $2,7 \%$ \\
\hline Cleft/ lip palate plasty, angioma, cyst & 41 & $6,4 \%$ \\
\hline Neck explorations for lipoma, thyroglossal cyst lymphangioma, dermatofibroma & 42 & $6,6 \%$ \\
\hline Biopsy or neck dissection & 14 & $2,2 \%$ \\
\hline Incision and drainage of neck abscess & 4 & $0,6 \%$ \\
\hline Tympanoplasty/Mastoidectomy/Meatoplasty & 12 & $1,9 \%$ \\
\hline Other ear surgeries e.g. keloid & 17 & $2,7 \%$ \\
\hline Laryngeal surgery : Papillomatosis/keratotic lesion/epiglottic cyst & 7 & $1,1 \%$ \\
\hline Foreign bodies in the respiratory tract & 3 & $0,5 \%$ \\
\hline Tracheostomy & 3 & $0,5 \%$ \\
\hline Total laryngectomy with neck dissection & 2 & $0,3 \%$ \\
\hline Endonasal Polypectomy & 4 & $0,6 \%$ \\
\hline Sinus trephination for maxillary or frontal sinusitis & 3 & $0,5 \%$ \\
\hline Caldwell Luc procedure & 1 & $0,2 \%$ \\
\hline Antro-choanal polyp surgery & 2 & $0,3 \%$ \\
\hline Rhinoplasty for nasal stenosis / mass of nasal pyramid under local anesthesia & 2 & $0,3 \%$ \\
\hline Facial trauma & 1 & $0,2 \%$ \\
\hline Oropharynx/oral cavity surgery with excision of tumors of gingiva/oropharynx and neck dissections & 3 & $0,5 \%$ \\
\hline Transmaxillary Buccopharyngectomy & 1 & $0.20 \%$ \\
\hline Maxillofacial surgery : Palatal tumor/Ameloblastoma/ Angiofibroma/Hemimandibulectomy & 13 & $2,0 \%$ \\
\hline Excision nasolabial cyst & 1 & $0.16 \%$ \\
\hline Total & 637 & $100 \%$ \\
\hline
\end{tabular}
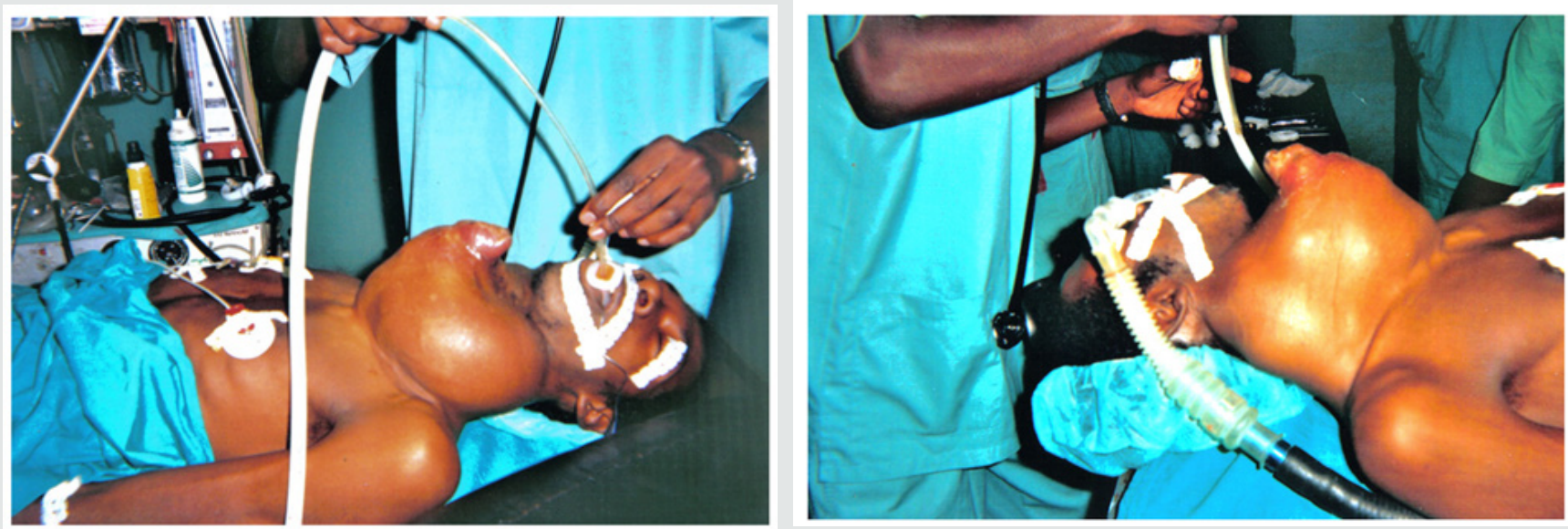

Figure 3a \& 3b: Operating Room Installation: Emergency decompression thyroidectomy in a 40-year-old man, followed by prophylactic tracheostomy, for massive vesicular carcinoma 


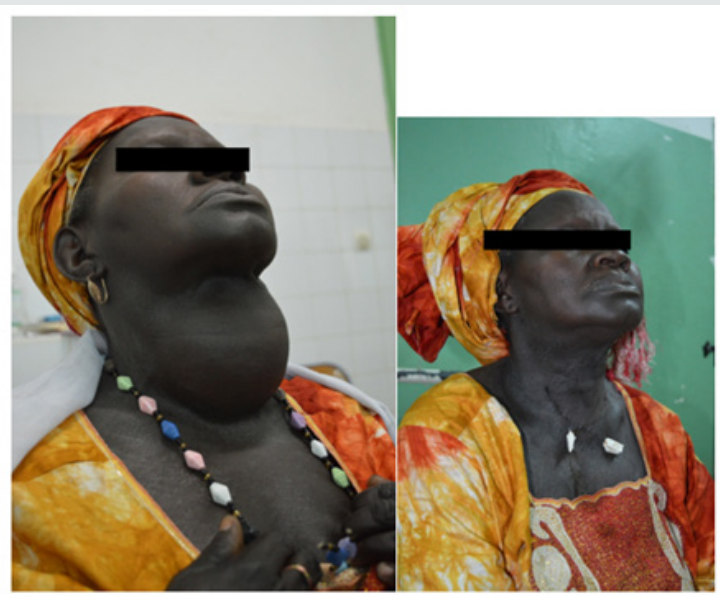

Figure 4a \& 4b: voluminous goitre seen before and after surgery operated during a mission in Sedhiou

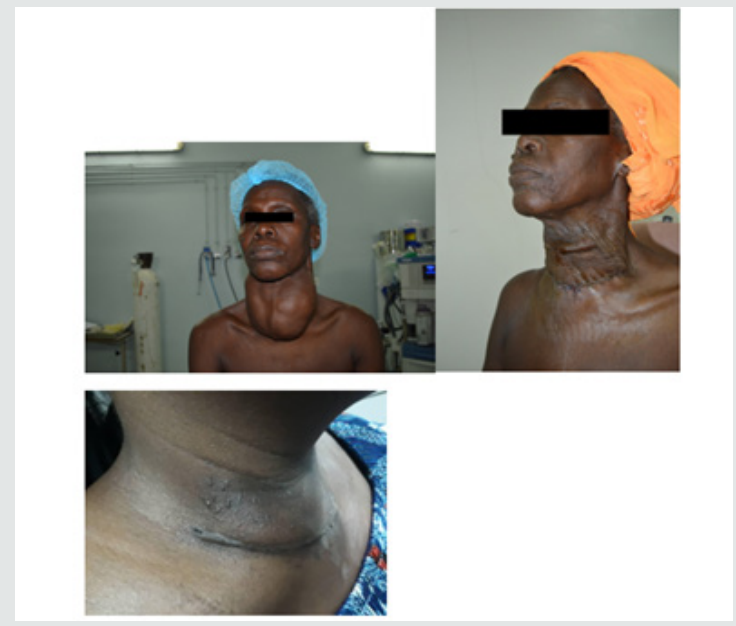

Figure 5a - 5c: Voluminous goitre seen before and after surgery operated during a mission in Ziguinchor. Scarification done by the traditional practitioner

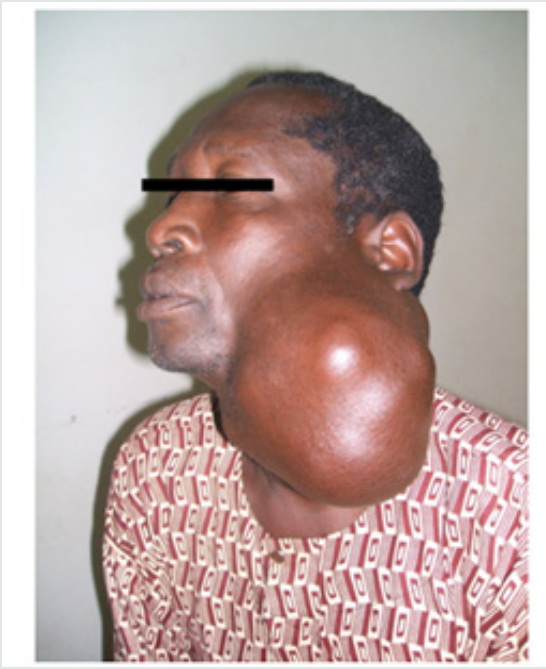

Figure 6: Voluminous parotid tumor that has been evolving for 26 years. 
However, some complex procedures such as total laryngectomy with neck dissection, transmaxillary buccopharyngectomy, mandibulectomy and sinonasal polyposis were performed during the missions. The operative specimens were taken back to Dakar for a histological examination, when it could not be done on site. Once the results were obtained, the local doctor was informed for a possible radiotherapy in Dakar.

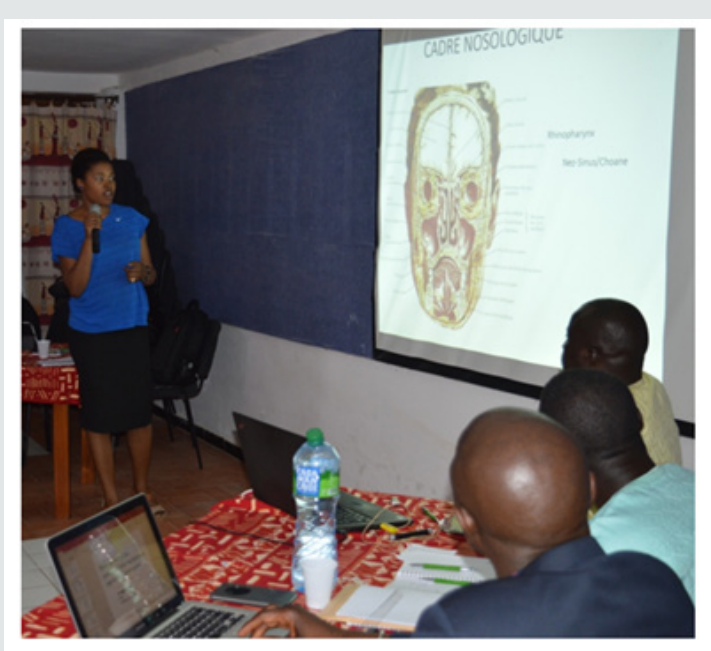

Figure 7: Teaching at the end of the mission.

Postgraduate teaching involved 10 lectures on themes chosen by the academic committee (Figure 7). The goal was to reinforce knowledge of local staff in the management of ENT emergencies. The titles were: Emergency tracheotomy: practical consideration (Saint Louis, Touba and Ziguinchor); foreign bodies of the lower respiratory tract (twice in Touba) ; ENT cancers (Ziguinchor) ; research project on hypopharyngeal cancer in Senegal (Touba) ; cholesteatoma of the middle ear: Which care in Africa? (Guinea Conakry) ; sensorineural hearing loss (Touba), and modern endoscopy in ENT (Touba).

\section{Discussion}

There is a great shortage of otorhinolaryngology and cervicofacial surgical services in Africa $[3,4]$. Malawi had only one ENT surgeon until 2016 for 18,090,000 inhabitants. The situation is also problematic for other countries in Southern Africa; Namibia has only 3 ENTs for 826,666 inhabitants and Botswana has 1 ENT and 1 for 750,000. In central Africa the Democratic Republic of Congo has only 25 ENTs for a population of fifty-five million, i.e. 1 ENT per 2,200,000 people. In Senegal, Diop [5] already pointed out in 1984 the severe shortage of ENTs in the east of the country. Consequently, populations of regions like Tambacounda or Matam are forced to travel several hundreds of kilometers $(467 \mathrm{~km})$ between Tambacounda and Dakar to access quality care. Regions such as Ziguinchor and Kaolack had only one ENT until 2016, which is clearly not sufficient for the number of inhabitants. Our study reports on 11 years of humanitarian ENT missions within Senegal carried out by the same team, with an average of 5 missions per year. In ENT, North-South or South-South cooperation systems are often described [6,7]. The system of cooperation and mutual aid within the same country or to a neighboring region is less common and not reported in journals [8]. Fornadley, Stern and Nathan [8] are American ENTs do so in the U.S. and describe it as "humanitarian effort in his own course". There is then an issue of "nomenclature". How to name this kind of locoregional oureach? Does this system exist in other African countries? In our study, the cities hosting the most missions are Tambacounda and Ziguinchor, (10 missions each). The main reason for this is the absence of ENT specialists in Tambacounda, which is the largest region in Senegal in terms of area $\left(59,602 \mathrm{~km}^{2}\right)$ and which had 607,000 inhabitants as of 2007 [9], and Ziguinchor which had one ENT for 523,840 inhabitants [9] as of 2016. The remoteness of these cities from the capital also limits access for the population to specialized care (467 $\mathrm{km}$ between Dakar and Tambacounda and $454 \mathrm{~km}$ between Dakar and Ziguinchor). Other cities like Thiès and Diourbel have only hosted 2 missions, because their own ENT departments are close to the capital: $70 \mathrm{~km}$ between Dakar and Thiès and $180 \mathrm{~km}$ between Dakar and Diourbel.

We noted a significant increase in the number of patient consultations per year. This is linked to expansion of mission sites from 2 sites in 2005 (Saint Louis and Tambacounda) to 6 sites in 2016 (Tambacounda, Ourossogui, Sédhiou, Kédougou, Kaolack and Kolda). The awareness and positive impact of the missions in the cities where they took place also contributed to the increased number of consultations. Thanks to the media coverage (radio broadcasts) at Kaolack Hospital, trend curves are for the most part upward, reflecting an increase in the number consultations over the years. These humanitarian missions initially focused on regions of Senegal but were then extended to Guinea Conakry with the support of the Senegalese-Guinean cooperation. They took place there twice (2009-2013). In practice, we learned during these missions that the help of translators was necessary, the consultations were longer, 
because explanations given to patients and their entourage (father, husband, guardian etc.) had to be clear to help with adherence to treatment. One facet of the ENT service, otology, was however limited in scope. This is related to the absence of diagnostic and surgical microscopes. Therefore, diagnosis and treatment of chronic otitis media is not being addressed, even though the initial reason for doing the outreach in the various Senegalese regions was to address chronic otitis media. In our study, chronic otitis media accounted for $22.1 \%$ of the consultations. This is comparable to those reported by Tabchib et al. [10] who found that chronic otitis media represent $20.5 \%$ of the series. This high prevalence of chronic otitis media emphasizes the importance of quickly acquiring a diagnostic microscope within a basic medical platform.

Gastroesophageal reflux was the second most common reason for consultation in our study $(18.3 \%)$ and was the most common pathology (36.2\%) in Kaolack in 2015. In 2016, in Tambacounda, gastro-oesophageal reflux (GERD) represented $25.3 \%$ of pathologies in consultation (in our study). The fear of the Senegalese ENT community is still the cancer of the hypopharynx, as it is the main (47\%) ENT cancer in Senegal [11], of which gastric reflux is one of the risk factors. Indeed, many studies have revealed a particular epidemiological profile for cancer of the hypopharynx in Senegal, where smoking and alcoholism are uncommon [11]. In many regions, the fiberoptic gastroscopy is not always accessible and ENT is practiced in an outpatient clinic setting. Allergic rhinitis was ranked as the third most frequent reason for consultation in our study (15.1\%); clinical and skin test assessments were used to make a diagnosis. However, it was the most common ENT pathology as reported by Tall [12] in rural southern Senegal (67.6\%); Ngom et al. [13], reported a rate of $45.5 \%$. These rates are much higher than those of our study. This can be explained by the sample size on the one hand, and by when the mission took place, as allergic rhinitis is a pathology strongly influenced by the rainy season. Goiter is a cosmopolitan condition $[14,15]$, and its frequency and clinical varieties differ between countries and regions. In our study goiters have a prevalence of $2.3 \%$ and were characterized by their considerable size. This is due to the fact that patients usually consult late, only after having tried various medications or traditional medicine. Surgery has been a big part of our humanitarian activities, with nearly seventy different types of surgical procedures being performed during the missions. Procedures were dominated by head and neck surgery. Because of the critical issue of financial means, we learned that ENT consultation equipments (Clar's frontal mirror, etc.) needed to be provided; drugs, DELBET drain for cervical wounds, magnifying glasses etc. Lack of resources has developed cleverness and recourse to makeshift solutions. Drainage was done for all cervical surgeries. Surveillance of tracheotomized patients was done by our team. There was a lack of ENT activity, so there were few nurses who really knew how to follow an ENT patient.

The poor otological component was due to the lack of an operating microscope, although some colleagues use the endoscope for simple surgery such as myringoplasty [16]. The other solution, outside the endoscope was the transfer of the patient to one of the public hospitals in the capital, with prior preparation: reduction of the waiting list for this patient, rapid organization of surgery in the city. Parents of children having undergone cleft lip and palate surgery were very grateful. However, the surgical activities encountered difficulties during certain missions. In Diourbel, in 2008, a patient died during a surgical procedure due to a lack of blood. In Saint Louis, in 2015, a strike by SUTSAS (the single union of health workers) disrupted the operative planning, forcing the program to be reorganized to focus on prioritizing the most urgent patients. Outside the care component, our missions were aimed at organizing teaching on ENT emergencies, and to discuss difficult cases. These lectures were led by professors and generated enthusiasm with the local ENTs. A similar example/experience is reported in Cambodia [7]. We learned that exchanges with local teams should be based on humility, because the few on-site ENT surgeons managed to take care of many cases using very limited resources. As far as our team is concerned, residents encountered many popular beliefs; for example, an otorrhea in their small child is not a pathology for many mothers, but remains of amniotic fluid that must flow. Other examples are even more disturbing: the treatment of turbinal hypertrophy by traditional practitioners was utilizing a very inadequate equipment. Cervical scarifications were often found in patients with goiters or cervical lymphadenopathy. Our residents needed to use social intelligence and tact to avoid hurting feelings, by explaining with simple and pictorial words the pathologies to the patient.

Under-medicalization was at the origin of late diagnosis of numerous cases of thyroid and parotid tumors of considerable size. This experience contributed to practical surgical experience for residents, companionship, exposure to a traditional system of knowledge transfer, and overall educational training. Indeed, this experience for the young residents accompanying senior team members was productive for the student, surgery procedures were more accessible. These beneficial aspects are also reported by Jafari [17]. Humanitarian missions during residency are seen as worthwhile; they may provoke interest in future humanitarian efforts, as described by this American author [17] on otolaryngology trainee recipients of the American Academy of OtolaryngologyHead and Neck Surgery Foundation; humanitarian travel grants; they may also positively affect competency-based metrics. The knowledge gained from these missions has led to develop a new system of cooperation between the various healthcare providers in Senegal, so as to significantly increase access to ENT care in Senegal. Indeed, given the success met early in the missions, the team repeated these activities over 11 years. The providers of the university team have increased in number as well as the residents of the specialty. This system of cooperation has therefore become a well-regulated humanitarian activity as an integral part of the training program for interns. There is now a rotation with 10 different teams currently crisscrossing 10 regions every year on specific dates. Humanitarian activities therefore end up serving as the backdrop for training. 


\section{Conclusion}

These missions have a definite benefit, they have allowed poor populations to access quality specialist care; to promote the ENT specialty in remote hospitals; and to increase the quality of ENT in regional hospitals through teaching and training. The number of surgical procedures and the advanced stage of the surgically treated pathologies highlighted the urgency to create regional ENT surgery units. This new system, developed after 11 years of experience and 66 missions, can be adapted to other countries or regions of the world suffering from a similar lack of experienced otolaryngologic care.

\section{References}

1. Doctor order Table in Senegal in 2016.

2. WHO (2008) World Health Statistics Statistiques sanitaires mondiales.

3. Fagan J, Jacobs M (2009) Survey of ENT services in Africa : need for a comprehensive intervention. Glob Health Action 2: 10.3402/gha. v2i0.1932

4. Mulwafu W, Ensink R, Kuper H, Fagan J (2017) Survey of ENT services in sub-Saharan Africa: little progress between 2009 and 2015. Glob Health Action 10(1):1289736.

5. Diop EM, Toure P, Diop LS (1984) Head and Neck Carcinology Medecine dAfrique noire 31(11): 593-601.

6. Gallas D, Londero A, Teissier N, Nicollas R, Malinvaud D, et al. (2014) Third French ENT humanitarian mission in Ecuador. French Annals of Otorhinolaryngology and Cervico-Facial Pathology 4(131): 55.

7. Gardini B, Corre A, Bruzzo M (2014) Otological Surgery in Cambodia: seven years of experience of the Hear the World Association. Annales francaises d Oto-Rhino-Laryngologie et de pathologie cervico-faciale 129(4): 47.
8. Fornadley J, Stern W, Nathan Ca (2015) Head and neck cancer a humanitarian effort in your own backyard. Ear Nose Throat J 94(2): 5456.

9. NSDA (2016) National Statistical And Demographic Agency (NSDA). Projections Department of Demographic and Social Statistics, Census and Demographic Statistics Division.

10. Tabchi B, Rassi S, Haddad A, Nehme P, El Rassi B (2000) Suppurative chronic otitis media: an experiment of 140 cases collected at l'hôtel Dieu de France. J Med Liban 48(3): 152-156.

11. Ndiaye Ic, Diom Es, Diop F, Tall A (2009) Squamous carcinoma of the hypopharynx in children in Senegal: between disarray and enigma. Int J Pediatr Otorhinolaryngol 73(3): 357-361.

12. Tall H, Diom Es, Diouf Ms, Kossinda F, Ndiaye N, et al. (2015) Evaluation of the otorhinolaryngological activity from August 1, 2010 to March 31, 2011 at the Regional Hospital of Kolda (Senegal). Med d Afr Noire 2(6): 13-15.

13. Ngom Abdou Ks, Koffin, Blessy M, Aka Danguye, Meless T (2006) Respiratory allergies of the child and the adult in an African environment. Epidemiological approach through a prick test. Med d'Afr Noire 53: 2933.

14. Toure A, Diallo At, Camara Lm, Toure Fb, Camara Nd (2008) Thyroid surgery: experience of the general surgery department of the academic hospital of Ignace Deen Conakry. Mali medical 3(21): 23-27.

15. Dia Dg, Tall H, Tendeng Jn, Dia Ad, Dieng Il, et al. (2016) Epidemiological, clinical and ethological profile of goitres in Saint Louis Senegal, Revue Africaine de Medecine Interne 3(1): 1-3.

16. Clark MPA (2018) Endoscopic ear surgery in the ear camp setting; forward thinking or folly? J Laryngol Otol 132(1): 68-70.

17. Jafari A, Tringale Kr, Campbell Bh, Husseman Jw, Cordes S (2017) Impact of Humanitarian Experiences on Otolaryngology Trainees: A Followup Study of Travel Grant Recipients Otolaryngology-Head and Neck Surgery 156(6): 1084-1087.

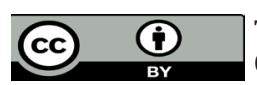

This work is licensed under Creative Commons Attribution 4.0 License

To Submit Your Article Click Here: Submit Article

DOI: $10.32474 /$ SJO.2020.03.000171

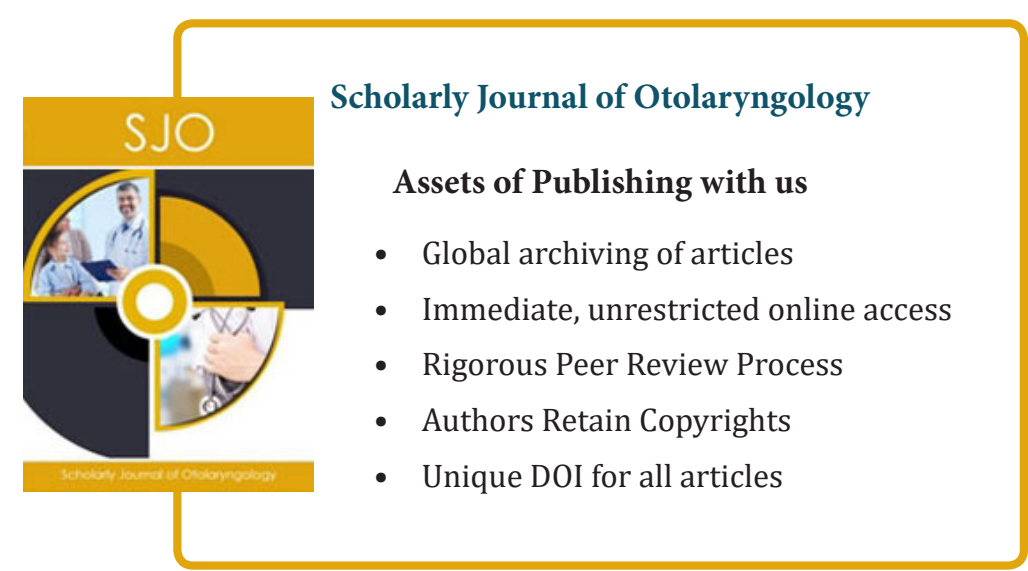

